ISSN 2227-9717

www.mdpi.com/journal/processes

Article

\title{
A Novel Seeding and Conditioning Bioreactor for Vascular Tissue Engineering
}

\section{Julia Schulte ${ }^{1}$, Anja Friedrich ${ }^{2}$, Trixi Hollweck ${ }^{1}$, Fabian König ${ }^{1}$, Markus Eblenkamp ${ }^{2}$, Andres Beiras-Fernandez ${ }^{3}$, Cornelia Fano ${ }^{4}$, Christian Hagl ${ }^{1}$ and Bassil Akra ${ }^{1, *}$}

1 Department of Cardiac Surgery, Laboratory for Tissue Engineering, Medical Center Munich University, 81377 Munich, Germany; E-Mails: julia.schulte@med.uni-muenchen.de (J.S.);

trixi.hollweck@med.uni-muenchen.de (T.H.); fabian.koenig@med.uni-muenchen.de (F.K.);

christian.hagl@med.uni-muenchen.de (C.H.)

2 Institute of Medical and Polymer Engineering, Technische Universität München, 85748 Garching, Germany; E-Mails: anja.friedrich@mytum.de (A.F.); markus.eblenkamp@tum.de (M.E.)

3 Department of Thoracic and Cardiovascular Surgery, Johann Wolfgang Goethe University, 60590 Frankfurt, Germany; E-Mail: andres.beiras@kgu.de

4 Institute of Textile Technology and Process Engineering, 73770 Denkendorf, Germany;

E-Mail: cornelia.fano@itv-denkendorf.de

* Author to whom correspondence should be addressed; E-Mail: bassil.akra@med.uni-muenchen.de; Tel.: +49-089-4400-76465; Fax: +49-089-4400-78873.

Received: 10 February 2014; in revised form: 21 May 2014 / Accepted: 20 June 2014 /

Published: 8 July 2014

\begin{abstract}
Multiple efforts have been made to develop small-diameter tissue engineered vascular grafts using a great variety of bioreactor systems at different steps of processing. Nevertheless, there is still an extensive need for a compact all-in-one system providing multiple and simultaneous processing. The aim of this project was to develop a new device to fulfill the major requirements of an ideal system that allows simultaneous seeding, conditioning, and perfusion. The newly developed system can be actuated in a common incubator and consists of six components: a rotating cylinder, a pump, a pulse generator, a control unit, a mixer, and a reservoir. Components that are in direct contact with cell media, cells, and/or tissue allow sterile processing. Proof-of-concept experiments were performed with polyurethane tubes and collagen tubes. The scaffolds were seeded with fibroblasts and endothelial cells that were isolated from human saphenous vein segments. Scanning electron microscopy and immunohistochemistry showed better seeding success of polyurethane scaffolds in comparison to collagen. Conditioning of polyurethane tubes with
\end{abstract}


$100 \mathrm{dyn} / \mathrm{cm}^{2}$ resulted in cell detachments, whereas a moderate conditioning program with stepwise increase of shear stress from 10 to $40 \mathrm{dyn} / \mathrm{cm}^{2}$ induced a stable and confluent cell layer. The new bioreactor is a powerful tool for quick and easy testing of various scaffold materials for the development of tissue engineered vascular grafts. The combination of this bioreactor with native tissue allows testing of medical devices and medicinal substances under physiological conditions that is a good step towards reduction of animal testing. In the long run, the bioreactor could turn out to produce tissue engineered vascular grafts for human applications "at the bedside".

Keywords: tissue engineering; bioreactor; vascular graft; polyurethane; collagen; decellularized tissue

\section{Introduction}

Chronic ischemic heart disease, coronary artery disease, and cardiac infarction are the most common causes of death worldwide, accounting for $25.6 \%$ of all fatal casualties [1]. They are predominantly caused by a restriction of the coronary circulation which is commonly affected by atherosclerotic occlusion [2].

The use of patient's native veins to replace faulty blood vessels is still the silver bullet in clinical practice [3,4]. Although minimal invasive techniques seem to outstrip the conventional vascular replacement [5], surgical bypass is still performed in numerous patients [6]. Coronary artery bypass grafting (CABG) using intact autologous veins results in less events of stroke, myocardial infarction (MI) or repeated revascularization in long-term application compared to percutaneous coronary intervention (PCI) [7,8]. The results of the SYNTAX (Synergy between PCI with TAXUS (paclitaxel-eluting stents) and Cardiac Surgery) study from 2011 [9,10] permit the identification of patients that have a greater benefit from bypass surgery instead of PCI.

For patients who cannot be treated with PCI and/or for patients who do not possess adequate autologous vessel material for CABG, there is still an increasing need for new innovative implants [11]. Native vessels and conventional polytetrafluoroethylene (PTFE) grafts show various limitations like re-occlusion, aneurysm formation and/or thrombogenicity. Processing techniques for artificial grafting aim to overcome these limitations by enabling the development of smaller graft diameters (inner diameter $<6 \mathrm{~mm}$ ) $[4,12,13]$.

Currently, there are multiple approaches under investigation to develop an ideal graft. Apart from a small number of scaffold-free concepts, organic or synthetic, degradable or non-degradable scaffolds are in common use [4].

An untreated surface often leads to rejection, requiring coatings like heparin to avoid occlusion by clotting [14] or paclitaxel to suppress hyperplasia [15]. The different coatings have a significant positive impact on the performance of the scaffold material, but the integrity of these coatings is usually compromised at high flow rates [16]. Another promising strategy is the seeding of the graft with endothelial cells (ECs) [17,18]. This unstable cell-matrix-interaction can be supported and guaranteed by pre-seeding the new prosthesis with vascular fibroblasts (FBs), which mimic the cellular 
structure of healthy subjects $[19,20]$. Various cell sources like stem cells [21], endothelial progenitor cells [22] or isolated vascular ECs [23] are under investigation for graft seeding. Depending on their origin, stem cells are reported to have a high growth and repair potential in many cases [24-26]. The use of embryonic stem cells for therapeutic purposes is subject to ethical and legal concerns, and thus they are not currently utilized for tissue engineering investigation. Tumor formation is an actual risk of embryonic stem cells due to their indefinite propagation as well as immunologic intolerance caused by the allogeneic nature [24,26-28]. Without any ethical concerns, adult stem cells can be derived from the patient and are therefore autologous in nature. Additional possible sources are bone marrow, peripheral blood, skeletal muscle, and, in the long term, placental cord blood. However, the induced transdifferentiation of adult stem cells at the necessary efficiency is infeasible. If these disadvantages remain unsolved embryonic and adult stem cells cannot be regarded as standard options for tissue engineering [26,27,29].

In contrast, autologous differentiated ECs derived from the saphenous vein segments do not require any immune suppression and have no carcinogenic potential. This safe cell source comes at the cost of an invasive surgical procedure to harvest intact vascular donor tissue [30].

In addition to material surface modification, it is known that shear stress and transmural pressure influence the shape and biosynthesis of vascular cells. The effects are structural remodeling and flattening of ECs as well as activation of signaling cascades [31,32]. If signals are inappropriate or missing altogether, cells proliferate only poorly and lose cell-cell contacts and the ability to form organized tissues $[33,34]$. The cells dedifferentiate and no extracellular matrix (ECM) is established. In summary, mechanical stress is essential for the achievement of a good quality ECM [35].

Due to these essential conditions for the development of a cell-based graft, different bioreactors have been developed recently to simulate physiological conditions, such as temperature, blood flow, shear stress or mechanical strain. These systems play a crucial role in building tissue engineered constructs [36]. They can be used for seeding and conditioning as well as for mechanical stress tests under physiological conditions [37]. As a general rule, the development of tissue-engineered implants should be realized in a sterile system under stable physiological conditions (shear stress and blood flow) $[17,31,38,39]$, which allows for reproducible and low cost processes. Bioreactors should enable the observation of different parameters like $\mathrm{CO}_{2}$, nutrients and growth factors to guarantee a good manufacturing practice [40].

So far, only few research groups have developed bioreactors with the capability to simultaneously perform dynamic seeding and pulsatile flow processes of multiple grafts under physiological conditions [41-48]. Therefore, the aim of this study was to develop an all-in-one bioreactor (BR) offering comparative test results, adjustable process parameters and simple handling.

\section{Experimental Section}

\subsection{Bioreactor Development}

\subsubsection{Construction}

All parts of the bioreactor (BR) were designed using the computer-aided software CatiaV5R19 (DassaultSystèmes, Vélizy-Villacoublay, France). Non-electric BR components were manufactured 
in-house. Parts that are in contact with cell media, cells, and/or tissue were developed such as to allow reprocessing. The BR system consists of six components: a seeding cylinder, a rotating mixer, a media reservoir, a control unit, a roller pump, and a pulse generator. All parts are assembled on a square ground plate made of polyvinylchloride (PVC) with a length $l=400 \mathrm{~mm}$ and height $h=15 \mathrm{~mm}$. The dimensions allow the actuation of the bioreactor in a standard incubator.

\section{Seeding Device}

The seeding device (Figure 1) comprises a cylinder filled with cell culture medium surrounding the tissue engineered vascular graft (TEVG). In the cylinder, two pairs of fixed vessel cannulas allow a simultaneous perfusion of two TEVGs. The housing of the cylinder with an outer diameter $D=65 \mathrm{~mm}$, an inner diameter $d=46 \mathrm{~mm}$, an outer height $H=155 \mathrm{~mm}$, and an inner height $h=130 \mathrm{~mm}$ is made from polymethyl methacrylate (PMMA) and narrows to $d=15 \mathrm{~mm}$ at the tip. The cylinder has a guide rail (depth $=15 \mathrm{~mm}, l=10 \mathrm{~mm}$ ) to secure the cylinder position on the mixer. At the base, a metric thread (M64 $\times 1.5)$ is milled to lock the cylinder with a screw cap $(D=73 \mathrm{~mm}, d=48 \mathrm{~mm}, h=15 \mathrm{~mm})$ and a step (depth $=14 \mathrm{~mm}$ ) with $d=55 \mathrm{~mm}$ is created to countersink the integrated scaffold carrier of the seeding device.

Figure 1. Transversal section (a) and top view (b) of the seeding device composed of a cylindric housing (1) with screw cap (2). The scaffold carrier with an outlet (3) and an inlet (4) is adjusted with four spacers (5) and allows the simultaneous perfusion of two tissue engineered vascular grafts (TEVGs) (6). The scaffolds are fixed with vessel cannulas (7) while the spacers are fixed with screw nuts (8). Luer-Lock-adapters (9) simplify filling processes and connection to the tubing system.

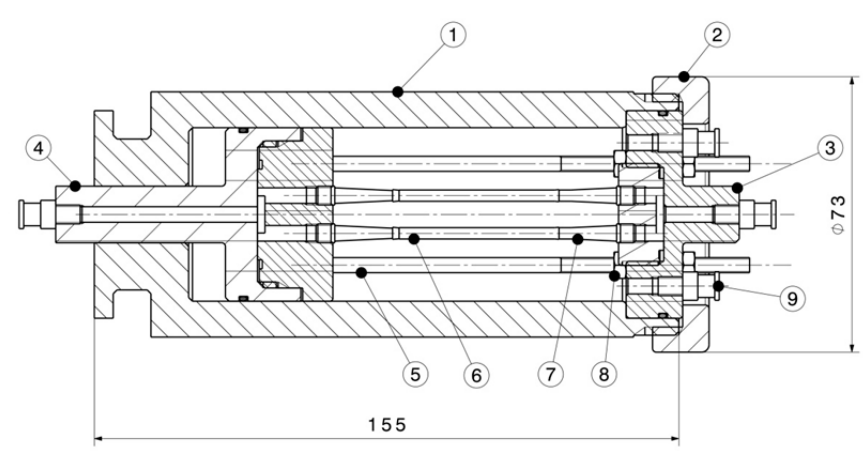

(a)

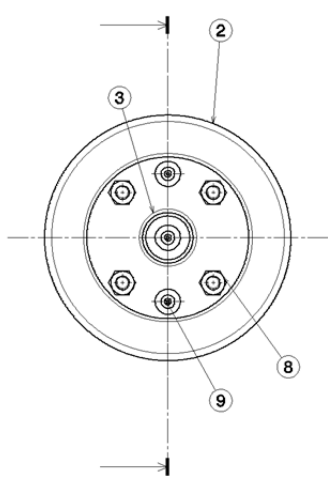

(b)

The scaffold carrier of the seeding device is composed of an outlet (Figure 1, (3), $d=46 \mathrm{~mm}$, $h=28.5 \mathrm{~mm}$ with a nose of $d=15 \mathrm{~mm}, h=45 \mathrm{~mm}$ ) and an inlet (Figure 1, (4), $d=55 \mathrm{~mm}, h=15 \mathrm{~mm}$ with a nose of $d=15 \mathrm{~mm}, h=15 \mathrm{~mm}$ ) made of polyoxymethylene (POM). Both elements are composed of two parts to generate branched supply channels, shown in detail for the outlet in Figures 2 and 3.

The distance of the inlet and the outlet is regulated by four spacers made of medical grade steel (Figure 1, (5), $d=4 \mathrm{~mm}, h=150 \mathrm{~mm}$ ) that are positioned in a radius of $38 \mathrm{~mm}$. The BR channels (Figure 1, (1)) with a diameter of $4 \mathrm{~mm}$ are arranged parallel in a distance of $10 \mathrm{~mm}$. The Luer-Lock 
adapters for the vessel grafts are countersunk into the channels. Two rotatable Luer-Lock connectors are mounted on the inlet and outlet to allow parallel rotational seeding and perfusion procedures. Two additional Luer-Lock connectors are attached to the lid for filling processes. O-rings are used as sealing elements to ensure fluid transport without leakage. The scaffold carrier is positioned into the seeding cylinder and secured by the closure of the lid.

Figure 2. Top view (a), bottom view (b) and transversal section (c) of the outer part of the outlet with a bore hole (1) for the perfusion media, a bore hole (2) for filling the seeding cylinder, a bore hole (4) for the spacers, a thread (3) for screwing the inner part of the outlet in place and an indentation (5) to keep a gasket in place.

a

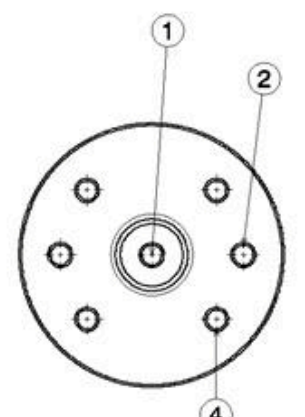

b

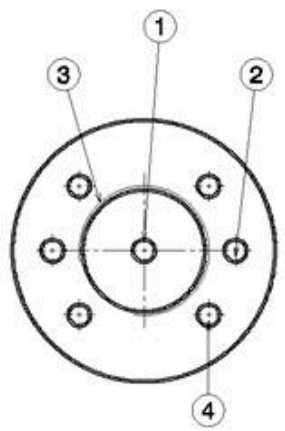

C

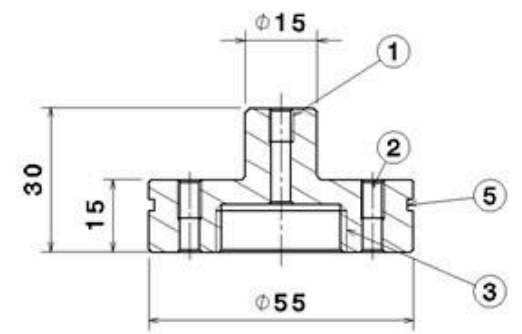

Figure 3. Top view (a), bottom view (b) and transversal section (c) of the inner part of the outlet with a bore hole (1) for perfusion media, a furrow (2) to generate a branched supply channel and a thread (3) for screwing the inner part of the outlet in its outer part.

a

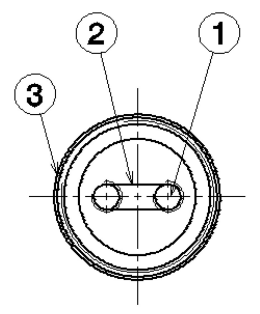

b

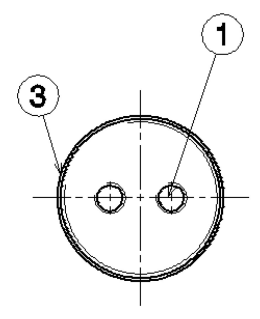

C

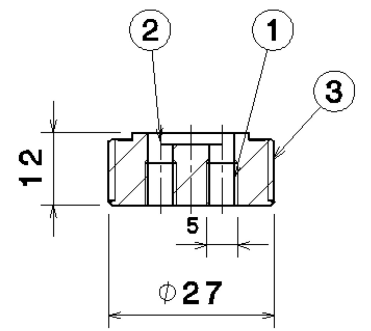

The seeding device has a maximum capacity of $130 \mathrm{~mL}$, depending on the spacer offset. It has an outer radius of $65 \mathrm{~mm}$ and an overall length of $200 \mathrm{~mm}$ with a net weight of $600 \mathrm{~g}$.

Mixer

For dynamical rotation the seeding cylinder is placed on the mixer (Figure 4). All external parts of the mixer are manufactured from aluminum. The design is based on commercially available roller mixers. Two drive shafts with $l=193 \mathrm{~mm}$ and narrowing diameters ( $d=20$ to $6 \mathrm{~mm})$ are mounted on a base with a distance of $61.5 \mathrm{~mm}$. Grooved ball bearings $(20 \times 32 \times 7 \mathrm{~mm}, 68042 \mathrm{RS})$ and miniature ball bearings $(6 \times 16 \times 15 \mathrm{~mm}$, S696A $2 \mathrm{RS})$ are used for each shaft. The front shaft is driven by a wheel $(D=68.5 \mathrm{~mm}, d=58.5 \mathrm{~mm})$, which is connected to a gear motor with a belt drive. The back shaft is connected with the first shaft by two wheels $(D=38 \mathrm{~mm}, d=28.5 \mathrm{~mm})$ and a belt drive. 
The rotation speed of the cylinder is at 13.4 RPM (rounds per minute). Two O-rings on each shaft and a guardrail prevent the seeding cylinder from slipping during rotation. A retaining bracket, locked by two spring-loaded latches, allows prompt fixation of the seeding cylinder.

Figure 4. Top view of the mixer (a) and a transversal section through the front shaft (b). The mixer is composed of two shafts (1), ball bearings $(2,3)$, and wheels $(4,5)$ for rotation. An O-ring (6) prevents the seeding cylinder from slipping. A guardrail (7) and a latch $(8+10)$ secure the seeding cylinder on the mixer. The shafts are assembled on a base (9).

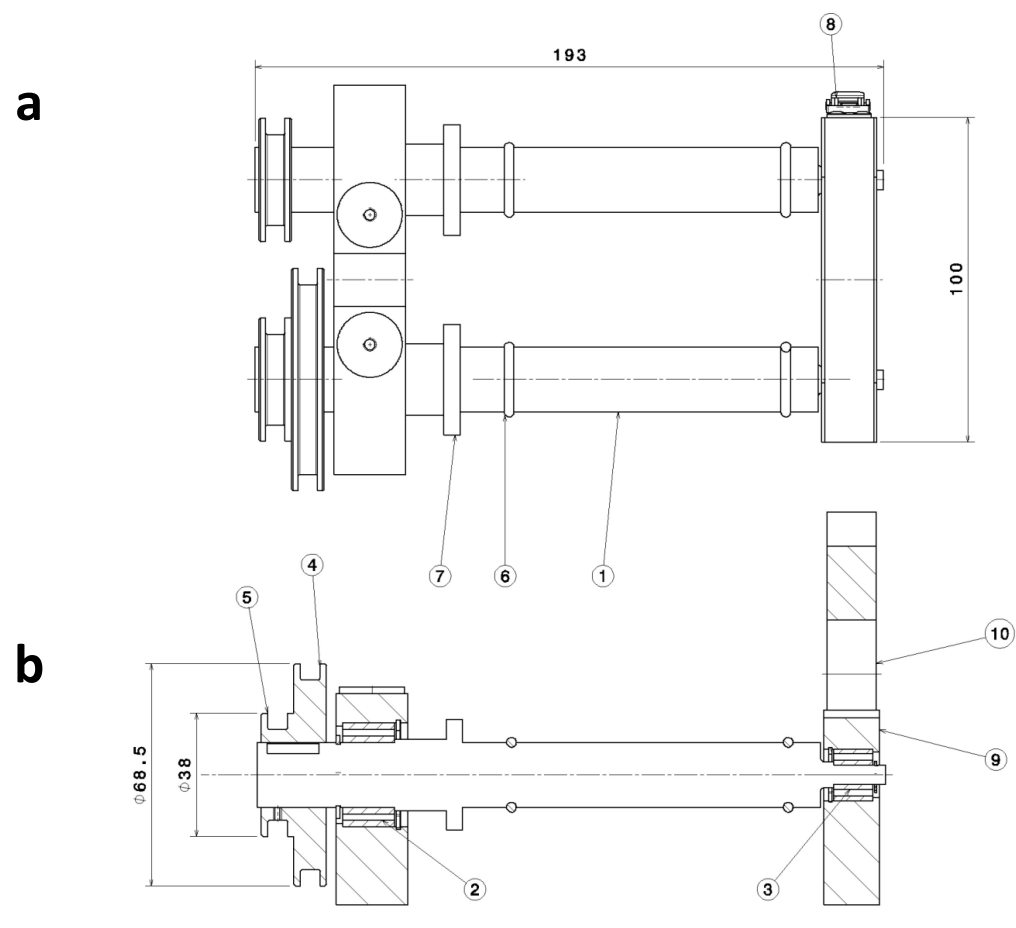

\section{Media Reservoir}

The media reservoir (Figure 5; $D=78 \mathrm{~mm}, d=58 \mathrm{~mm}, H=110 \mathrm{~mm}, h=100 \mathrm{~mm}$ ) is manufactured from PMMA and has a capacity of $220 \mathrm{~mL}$. Two Luer-Lock adapters are fixed to the reservoir wall in a distance of $15 \mathrm{~mm}$ and $30 \mathrm{~mm}$ to the reservoir bottom. The screw cap of the reservoir $(D=80 \mathrm{~mm}$, $d=58 \mathrm{~mm}, H=14 \mathrm{~mm}, h=7 \mathrm{~mm}$ ) contains four Luer-Lock adapters in a radius of $44 \mathrm{~mm}$. A gasket ring secures a tight closure of the reservoir.

The reservoir is placed in an aluminum stub $(D=89 \mathrm{~mm}, d=79 \mathrm{~mm}, h=10 \mathrm{~mm})$. An aluminum ring $(D=120 \mathrm{~mm}, h=6 \mathrm{~mm})$ enables the fixation to the ground plate via screws. The reservoir stub provides a gap of $20 \mathrm{~mm}$ for M5 Luer-Lock connectors of the reservoir. A M5 Teflon screw on the opposite side of the gap secures the position of the reservoir.

A peristaltic roller pump (WELCO Co. Ltd., Tokyo, Japan) is used for circulating perfusion through the BR. The speed of this pump is regulated by a speed controller (10 A, Conrad Electronic SE, Hirschau, Germany) with a potentiometer (wire-wound linear, 10 \&, 2 W, Conrad Electronic SE, Hirschau, Germany). The pump is combined with an eccentric device (pulser) driven by a DC-motor, which compresses the scaffold tubes periodically, resulting in a pulse right in front of the seeded scaffolds at a defined frequency of 60 beats per minute. This prevents a loss of impulse through the tubes. 
Figure 5. Transversal section (a) and top view (b) of the media reservoir of the bioreactor with a stub (1) screwed to the ground plate (2), a Teflon screw (3), M5-Luer-Lock adapters (4) in the cap (5) and further M5-Luer-Lock adapters (6) in the bottom.
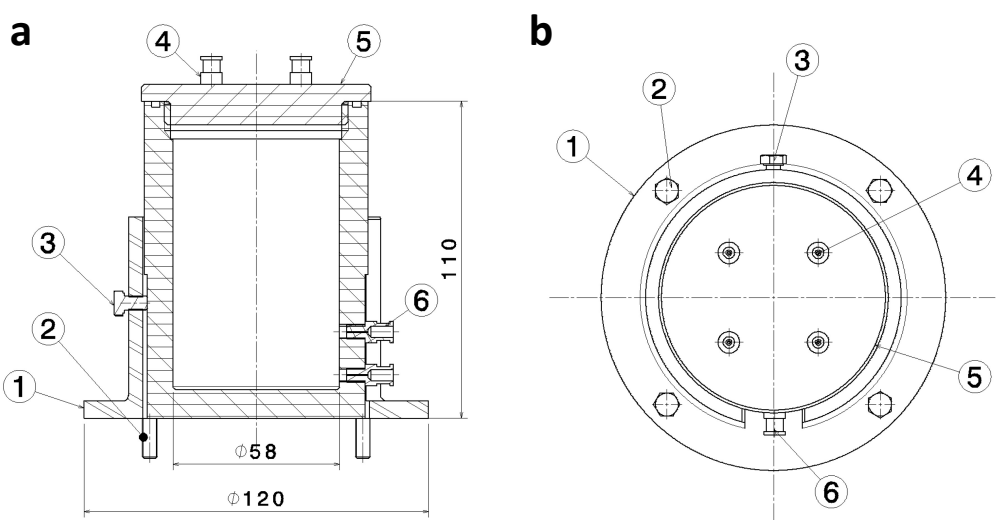

A programmable logic controller (PLC, Siemens LOGO! 12/14 RC, Siemens AG, Munich, Germany) was chosen to control all electronic devices by using the Logo! Soft Comfort software. The user panel with display and control buttons enables the control of the program parameters during the experiment.

Purchased parts were made of stainless steel (Luer-Lock connectors, ball bearings), medical grade polymers (tubing material), nylon (vessel cannulas), and nitrile butadiene rubber (NBR; O-rings). Medical laboratory equipment such as Luer-Locks (VBM Medizintechnik GmbH, Sulz, Germany; Hell \& Co GmbH, Diespeck, Germany), vessel cannulas (Vieweg GmbH, Kranzberg, Germany), syringe filters (Millex-GS, Merck Millipore, Merck KGaA, Darmstadt, Germany), medical tubes (Deutsch \& Neumann GmbH, Berlin, Germany), and tube connectors (Vieweg GmbH, Kranzberg, Germany) are CE marked sterile devices and are therefore qualified for the intended application.

\subsubsection{Sterilization}

The sterilization of the bioreactor is restricted to the components in contact with cells and/or cell culture medium; in detail, the seeding cylinder, the scaffold carrier, the reservoir, the tubing system, and the adapters. The sterilization was performed by formaldehyde deposition at $60-70{ }^{\circ} \mathrm{C}$ for $7 \mathrm{~h}$. Samples for sterilization verification were aseptically taken at 24, 72 and $96 \mathrm{~h}$ after incubation at $37{ }^{\circ} \mathrm{C} / 5 \% \mathrm{CO}_{2}$, and were screened for contaminations by conventional microbiological evaluation methods (Max-von-Pettenkofer-Institut für Hygiene und medizinische Mikrobiologie, University of Munich, Munich, Germany). Streak samples on Columbia-Blood agar, Cooked-Blood agar and MacConkey agar were incubated for $48 \mathrm{~h}$. Sabouraud agar in slant tubes with an incubation time for 5 days and liquid triptic soy broth with an incubation time of 10 days were used to detect contamination with candida.

\subsubsection{Functionality}

The bioreactor functionality was checked during a standard sequence as described in Sections 2.4.1 and 2.4.2, in the environment of a standard incubator at $37^{\circ} \mathrm{C}$ and $5 \% \mathrm{CO}_{2}$. The safe connection of all parts and the timed rotation as well as the start of perfusion and pulsation was ensured. The cell media 
was macroscopically inspected for cloudiness or color change through the transparent housings of the reservoir and the seeding device.

\subsection{Scaffold Materials}

Two different scaffold materials were selected for seeding with the bioreactor's setup: polyurethane (PU) and collagen (Figure 6).

Figure 6. A polyurethane (PU) tube $(\mathbf{a} ; l=60 \mathrm{~mm}, d=6 \mathrm{~mm})$ and a collagen tube (b; $l=60 \mathrm{~mm}, d=3 \mathrm{~mm}$ ).

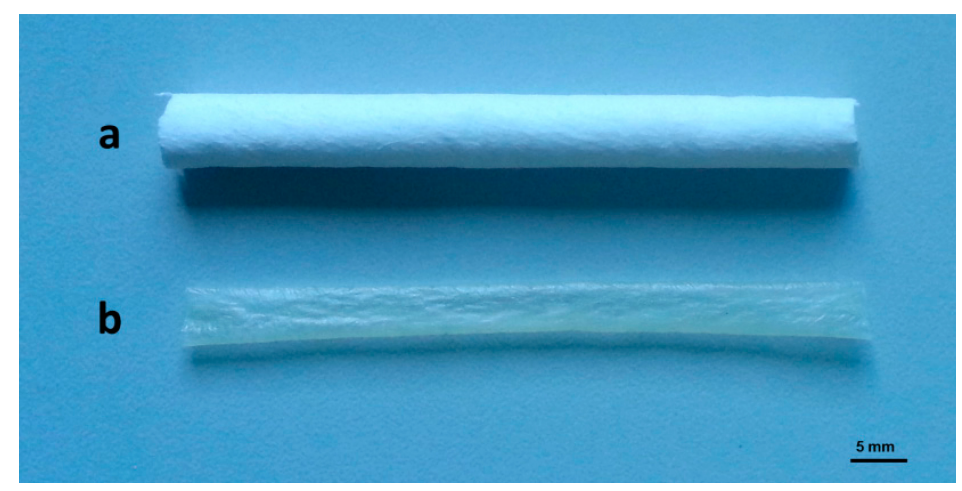

The PU vessel prostheses were manufactured by the ITV-Denkendorf (Denkendorf, Germany) using spraying technique [23]. Randomly oriented Polyurethane (PU) fibers offer a mean diameter of $1.55 \mu \mathrm{m}$ and form a tube with a wall thickness of $0.3 \mathrm{~mm}$ and an inner diameter of $6 \mathrm{~mm}$. For seeding purposes PU was $\gamma$-sterilized at $10 \mathrm{kGy}$ by a certified service provider for medical device sterilization.

Collagen tubes manufactured by using bovine origin material were supplied from Viscofan Bioengineering (Weinheim, Germany) free of charge. The tubes have an inner diameter of $3 \mathrm{~mm}$ and a length of $80 \mathrm{~mm}$.

\subsection{Cell Source}

\subsubsection{Cell Isolation and Sub Culturing}

ECs and FBs were isolated from remaining saphenous vein segments after bypass operations with the informed consent of patients. The average age of the treated patients is 71 years and $80 \%$ of them are men. Five to $12 \mathrm{~cm}$ long pieces of veins were stored at $4{ }^{\circ} \mathrm{C}$ in M199 media (Biochrom AG, Berlin, Germany) supplemented with $1 \mathrm{~mL}$ Penicillin-Streptomycin (5000 U and $5 \mathrm{mg} / \mathrm{mL}$, Sigma-Aldrich Chemie GmbH, Steinheim, Germany) for a maximum of 5 days until the isolation process. Segments were cannulized and rinsed with M199 containing 0.2\% heparin (5000 I.E., Ratiopharm GmbH, Ulm, Germany) and $0.5 \%$ gentamycin $(10 \mathrm{mg} / \mathrm{mL}$, Biochrom AG, Berlin, Germany). For EC isolation, veins were filled twice with $14 \mathrm{mg}$ collagenase II (280 U, Worthington Biochemical Corporation, Lakewood, NJ, USA) soluted in $10 \mathrm{~mL} \mathrm{1 \%} \mathrm{HSA} \mathrm{(human} \mathrm{serum} \mathrm{albumin,} \mathrm{CLS} \mathrm{Behring,} \mathrm{Bern,}$ Switzerland) and were each incubated for $15 \mathrm{~min}$ in PBS (Biochrom AG, Berlin, Germany) under physiological conditions in the incubator. Obtained cell suspensions were rinsed out, centrifuged for $7 \mathrm{~min}$ at $500 \mathrm{rpm}$ and finally cultivated in Endothelial Cell Growth Medium (ECGM, Promocell 
$\mathrm{GmbH}$, Heidelberg, Germany) supplemented with 6\% fetal calf serum (Lonza GmbH, Köln, Germany) and $0.2 \%$ penicillin/streptomycin (Sigma-Aldrich GmbH, Hamburg, Germany) in standard culture flasks (T12.5 $\mathrm{cm}^{2}$, Becton Dickinson $\mathrm{GmbH}$, Heidelberg, Germany) at $37{ }^{\circ} \mathrm{C} / 5 \% \mathrm{CO}_{2}$. For $\mathrm{FB}$ isolation, a coverslip method was used. The veins were sliced $\left(1 \mathrm{~mm}^{2}\right)$, transferred into a cell culture dish (NuncGmbH\& Co.KG, Wiesbaden, Germany), and placed below a coverslip fixed by silicone drops.

FBs cultivation was performed similarly to ECs using Fibroblast Growth Medium (FGM, Promocell $\mathrm{GmbH}$, Heidelberg, Germany) supplemented with $11 \%$ fetal calf serum and $0.2 \%$ penicillin/streptomycin, respectively. The medium was changed every 2-3 days. Cells were passaged at confluency in a ratio of $1: 14$ at $\mathrm{P} 1$ and in a ratio of $1: 3$ at $\mathrm{P} 2$.

\subsubsection{Cell Characterization}

FBs and ECs were phenotypically characterized by morphological observation and immunocytochemical staining (ICC) in eight-well-chamber slides (BD Bioscience, Franklin Lakes, NJ, USA) using specific antibodies as previously described [49]. Briefly, vascular cells were stained against EC-specific CD31 (10.25 $\mu \mathrm{g} / \mathrm{mL}$; Dako Deutschland GmbH, Hamburg, Germany) and FB-specific TE-7 (2 $\mu \mathrm{g} / \mathrm{mL}$, Millipore Corporation BioScience Division, Temecula, CA, USA), respectively, according to manufacturer's protocol using EnVision ${ }^{\mathrm{TM}}+$ Dual Link System-HRP (Dako Deutschland GmbH, Hamburg, Germany).

\subsection{Bioreactor Setups}

\subsubsection{Seeding Protocol}

The scaffold tubes-PU or collagen - were clamped to the Luer-Lock adapters in the scaffold carrier and were fixed with surgical threads (Ethicon, Johnson \& Johnson Medical GmbH, Norderstedt, Germany). The seeding device was assembled and filled with FGM. Then FBs $\left(750,000 \mathrm{cells} / \mathrm{cm}^{2}\right)$ were applied through the three-way stopcock disposed upstream of the seeding device and colonized on the scaffolds lumen by rotation on the mixer according to a defined seeding cycle for $7 \mathrm{~h}$. The cycle comprised rotation for $20 \mathrm{~s}$ clockwise and $30 \mathrm{~s}$ anti-clockwise with a holding phase of 20 min between each rotation. The seeding device stops at different points after each rotation phase and allows the cells to attach all over the scaffolds surface. 3 days after FB seeding, FGM was replaced by ECGM. ECs from the same donor $\left(750,000\right.$ cells $\left./ \mathrm{cm}^{2}\right)$ were seeded to the lumen in the same way and cultured for another 3 days. Samples were taken for immunohistochemistry (IHC) and scanning electron microscopy (SEM).

\subsubsection{Perfusion Protocol}

A preliminary perfusion experiment was performed with PU scaffolds $(n=3)$. Due to the low roughness of the pipe and the low Reynolds number, laminar flow could be assumed. The Reynolds number $(R e)$ is based on the mean velocity of the fluid $\left(v_{m}\right)$, the hydraulic diameter $\left(D_{h}\right)$ and the kinematic viscosity $(v)$

$$
R e=\frac{V_{m} \times D_{h}}{v}
$$


The mean velocity of the cell media $v_{m}$ is defined as the volumetric flow rate $(\dot{v})$ divided by the pipes cross-sectional area $(A)$

$$
V_{\mathrm{m}}=\frac{\dot{V}}{A}
$$

$D_{h}$ was $6 \mathrm{~mm}$ in the PU tube and the $v$ of the medium was measured to be about $1 \mathrm{~mm}^{2} / \mathrm{s}$. Hence Re was between five and 50, while a $R e>2200$ is known to cause turbulences in the system.

Twenty-four hours after FB-seeding with a rotation routine of the seeding cylinder as described above, each tube was perfused with a laminar flow of $12 \mathrm{~mL} / \mathrm{min}$ ( $\operatorname{shear}$ stress $=100 \mathrm{dyn} / \mathrm{cm}^{2}$ ) for 2 days.

After EC-seeding $\left(750,000\right.$ cells $\left./ \mathrm{cm}^{2}\right)$, the tubes were similarly perfused. After 6 days in total, the tubes were exposed to pulsatile flow conditions by actuating the pulse generator for $24 \mathrm{~h}$.

After the preliminary perfusion experiments the pump was modified. An optimized perfusion protocol was used. The seeding time was reduced to $6 \mathrm{~h}$ and the perfusion period was extended to $36 \mathrm{~h}$ with a smaller and stepwise increase of the shear stress from 10 to $40 \mathrm{dyn} / \mathrm{cm}^{2}$ (flow $=1.27 \mathrm{~mL} / \mathrm{min}$ to $5.1 \mathrm{~mL} / \mathrm{min}$ ), as shown in Figure 7. The pulse generator started $24 \mathrm{~h}$ after cell seeding with a break of $24 \mathrm{~h}$ of pulsation after EC seeding. Samples were taken for SEM and IHC.

Figure 7. Perfusion protocol of the conditioned TEVGs. After fibroblast (FB) seeding $(t=0 \mathrm{~h})$ the shear stress was gradually raised to $10 \mathrm{dyn} / \mathrm{cm}^{2}(t=6 \mathrm{~h})$ and $20 \mathrm{dyn} / \mathrm{cm}^{2}$ $(t=24 \mathrm{~h}$ ). Erythrocytes (ECs) were seeded at $t=48 \mathrm{~h}$ and were similarly perfused to FBs. The pulsation starts at $t=24 \mathrm{~h}$, stops after ECs seeding and restarts at $t=72 \mathrm{~h}$. After $96 \mathrm{~h}$ the shear stress was finally raised up to $40 \mathrm{dyn} / \mathrm{cm}^{2}$ for $1 \mathrm{~h}$.

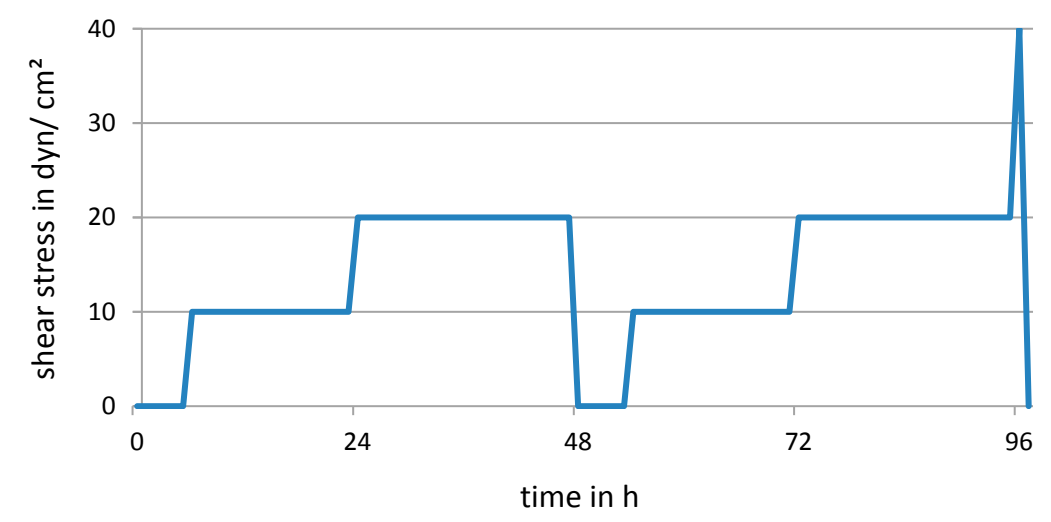

To validate the flow through the scaffold, the pressure was measured at different positions of the bioreactor. For all measurements, the pressure transmitter CPT2500 (WIKA GmbH, Klingenberg, Germany) was used in combination with the according drivers and software (USBsoft2500) and a customized adapter to allow integration of the sensor without influencing the running processes. The sensor allows measurements in the range of 0 to $300 \mathrm{mmHg}$ with a deviation of $\pm 3 \mathrm{mmHg}$ and was set to a sampling frequency of $100 \mathrm{~Hz}$. A time-frame of $30 \mathrm{~s}$ was measured to prevent any measurement errors or temporary effects to negatively influence the analysis. Measurements were taken without pulsation at flow rates of 10, 20, 40 and 100 dyn and under pulsatile conditions at flow rates of 20, 40 and 100 dyn. The measurement data was gathered with the USBsoft2500 software (WIKA GmbH, Klingenberg, Germany) exported into a umd file and finally processed using Excel 2010 and VBA (Microsoft Corporation, Redmond, WA, USA) to generate data fields and pressure-time curves. 


\subsection{Sample Evaluation}

\subsubsection{Scanning Electron Microscopy (SEM)}

SEM was used to examine the surface topography of native and seeded scaffolds. Specimens were fixed in a solution composed of $456 \mathrm{~mL}$ aqua bi-destillated (Ampuwa, Fresenius Kabi Deutschland GmbH, Bad Homburg v.d. H., Germany), $0.75 \mathrm{~mL} 1 \mathrm{~N}$ hydrochloric acid (Titrisol, Merck KGaA, Darmstadt, Germany), $43.5 \mathrm{~mL}$ glutaraldehyd and 5.65 g sodium cocodylatetrihydrate (Sigma-Aldrich Chemie GmbH, Steinheim, Germany) at $4{ }^{\circ} \mathrm{C}$ for $24 \mathrm{~h}$ at least. Samples were dehydrated in an ascending ethanol series $(30 \%, 50 \%, 70 \%$ and $96 \%)$ and subsequently in $99.9 \%$ ethanol at $-20{ }^{\circ} \mathrm{C}$. Specimens were dried at the critical point, sputtered with gold for $180 \mathrm{~s}$ at $10^{-5}$ mbar and analyzed using a SEM (EVO ${ }^{\circledR}$ LS 10; Carl Zeiss MikroImaging GmbH, Göttingen, Germany).

\subsubsection{Immunohistochemistry (IHC)}

Immunohistochemical analysis was performed to detect ECs and FBs after scaffold seeding. To this end, seeded samples were primarily fixed in $4 \%$ formaldehyde (Microcos $\mathrm{GmbH}$, Garching, Germany) for 10 days at $4{ }^{\circ} \mathrm{C}$. Fixed samples were paraffin-embedded and sectioned at $5 \mu \mathrm{m}$. Slices were stained against CD31 (ECs; $10.25 \mu \mathrm{g} / \mathrm{mL}$; Dako Deutschland GmbH, Hamburg, Germany) and TE-7 (FBs; $2 \mu \mathrm{g} / \mathrm{mL}$, Millipore Corporation BioScience Division, Temecula, CA, USA). Antigen retrieval was performed in the microwave with antigen retrieval solution at $\mathrm{pH} 9$ (Dako Deutschland $\mathrm{GmbH}$, Hamburg, Germany) for CD31 and with EDTA solution at $\mathrm{pH} 8$ for TE-7, respectively. Specimens were blocked for endogenous peroxidase and incubated with primary antibody at $4{ }^{\circ} \mathrm{C}$ overnight. After washing with PBS, samples were covered with biotinylated link for $10 \mathrm{~min}$ and HRP Streptavidin-label for 10 min according to manufacturer's protocol (HRP-Detection Kit, Biozol GmbH, Eching, Germany). Chromogen labeling was conducted for $10 \mathrm{~min}$ using AEC-Peroxidase-Substrate Kit (Vector Laboratories Inc., Burlingame, CA, USA). All incubation steps were performed at room temperature of $20{ }^{\circ} \mathrm{C}$. Cell nuclei were stained with hemalaun (1:4 in PBS; Merck KGaA, Darmstadt, Germany). Controls for non-specific binding of chromogen label were performed by excluding the primary antibody. A bright field microscope was used to examine all stained samples (Carl Zeiss MikroImaging GmbH, Göttingen, Germany).

\section{Results and Discussion}

\subsection{Bioreactor Assembly}

BRs for the generation of TEVGs are often bulky systems that require handling by highly trained persons [50-52].

The new BR is constructed in a way that allows an assembly in a laminar flow cabinet without any additional tools like screwdrivers or the need of saturation of the scaffolds to assemble them with the BR. As shown in Figure 8a, the novel all-in-one BR consists of six components: a seeding device (1) on a mixer (2), a media reservoir (3) a control unit (4) routing the gear motors for the mechanical components (2, 5 and 6), a peristaltic pump (5a) with modifiable speed, adjusted through a potentiometer (5b), and a pulse generator (6). A great benefit of the bioreactor is the compact assembly 
of the components on a stable baseplate. This allows for easy and quick handling and transportation, which grants stability during the entire experiment with seeding and conditioning processes.

Figure 8. (a) Rendering of the CATIA data of the all-in-one bioreactor with seeding device (1), rotating mixer (2), media reservoir (3), control unit (4), roller pump (5a) with potentiometer (5b) and pulse generator (6) and (b) the assembly of the all-in-one bioreactor (BR) with connection of all subunits via a simple tubing system.
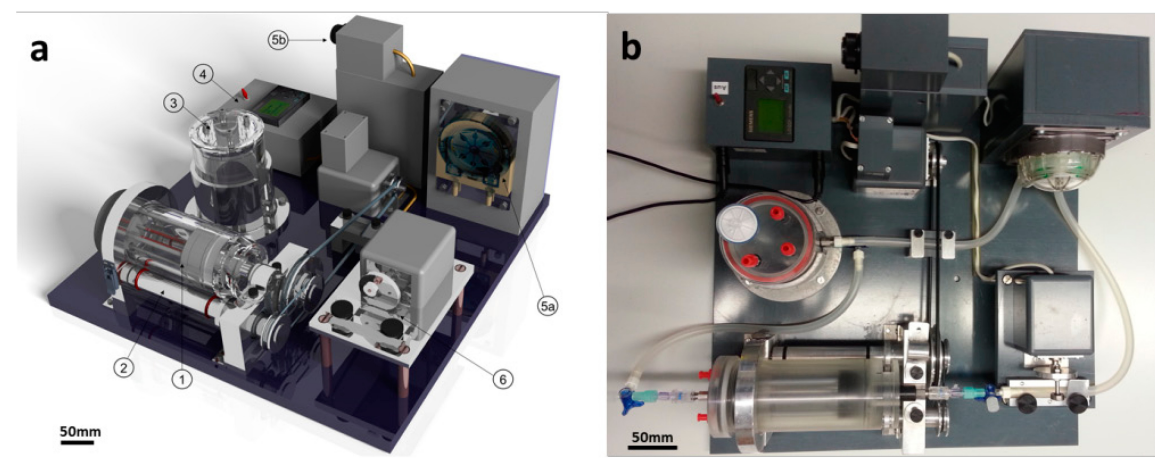

Figure 9. (a) Sectional view of the seeding cylinder with scaffolds (red), inlet (purple and violet), outlet (orange and yellow), spacers (green), Luer-Lock adapters (blue), housing (grey) and screw cap (brown); (b) final implementation of the seeding cylinder.
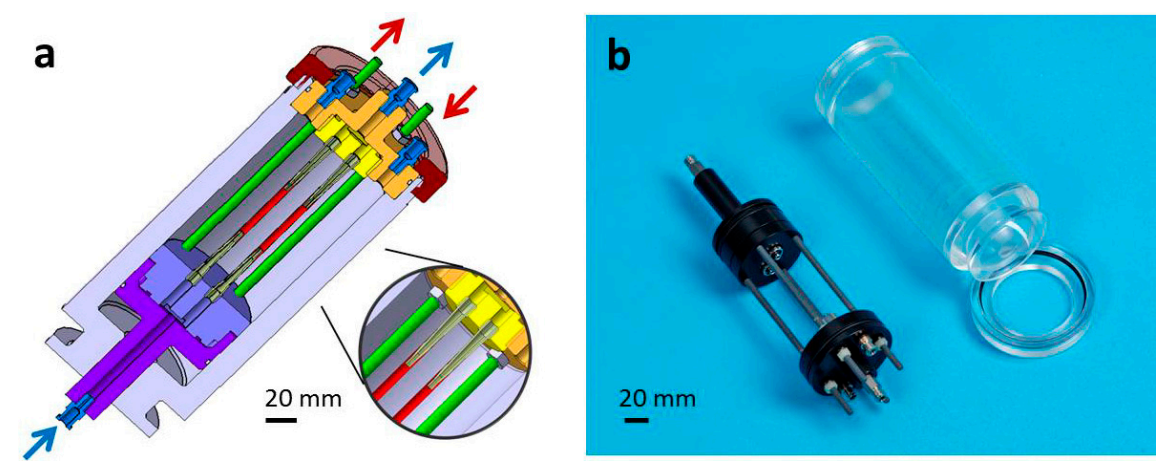

Two TEVGs can be attached to the seeding cylinder (Figure 9) and are connected to the tubing system for the perfusion procedure. In contrast to other systems [42,53,54], the dual fixture allows the comparison of different scaffold materials under the same settings and the preliminary seeding of the scaffolds in the same system lowers effort and vulnerability of the experiments. TEVGs (a, red) are located in the cylinder centre and are connected to the media circulation via standard Luer-Lock connectors (a, blue, flow in the direction of the blue arrows). The Luer-Lock connectors (a, blue, flow in direction of the red arrows) on the bioreactors outlet (a, orange and yellow) allow filling processes and media exchange. The scaffold carrier can be adjusted to the length of the TEVG by increasing the spacer distance (a, green). For connecting the vessel grafts to the scaffold carrier, the grafts are fixed with a surgical thread to the male Luer-Lock adapters with tube connectors. The tube connectors are assembled with the female Luer-Lock adapters of the inner parts of the inlet (a, violet) and the outlet (a, yellow). Finally, the scaffold carrier is inserted into the scaffolds housing and fixed by screwing the cap on top. Manufacturing of the seeding cylinder from PMMA provides optical transparency for macroscopic observation of processes within the unit (b). 


\subsection{Bioreactor Sterility}

Culture medium was checked for contamination during the bioreactor run at 24, 72 and $96 \mathrm{~h}$ by conventional streak samples two times. The microbiological evaluation was performed as previously described and showed no microbiological contamination. This indicates the feasibility of long-term dynamic studies under sterile conditions.

\subsection{Bioreactor Function}

Luer-Lock adapters with tube connectors ensure an easy connection of the BR components by tubes.

After filling the BR with media, sterile degasing of the tubing system can be quickly performed with a syringe via the three-way stopcocks. Using the three-way stopcock directly in front of the seeding device allows an accurate injection of the cell suspension to the scaffold for seeding purposes.

Pulsatile flow conditioning of the cells raises the tolerance of the tissue-engineered products to shear stress, pressure $[31,32,55]$ and thrombotic events [17].

The pressure measurements show comparable results at the different points of measurement. The main focus of interest lies in the flow position inside the graft, measurements were taken directly before and after the scaffold. Since these measurements showed similar results, only the measurements directly before the scaffold are shown (Table 1, Figure 10).

The pressure pattern showed similar data (Table 1) for different shear stress forces without pulsation while pulsatile flow leads to a pattern near to physiologic conditions in small venoles.

Figure 10. Pressure pattern for $30 \mathrm{~s}$ in the PU scaffold under pulsatile flow with $20 \mathrm{dyn} / \mathrm{cm}^{2}$ (red), $40 \mathrm{dyn} / \mathrm{cm}^{2}$ (blue) and $100 \mathrm{dyn} / \mathrm{cm}^{2}$ (green).

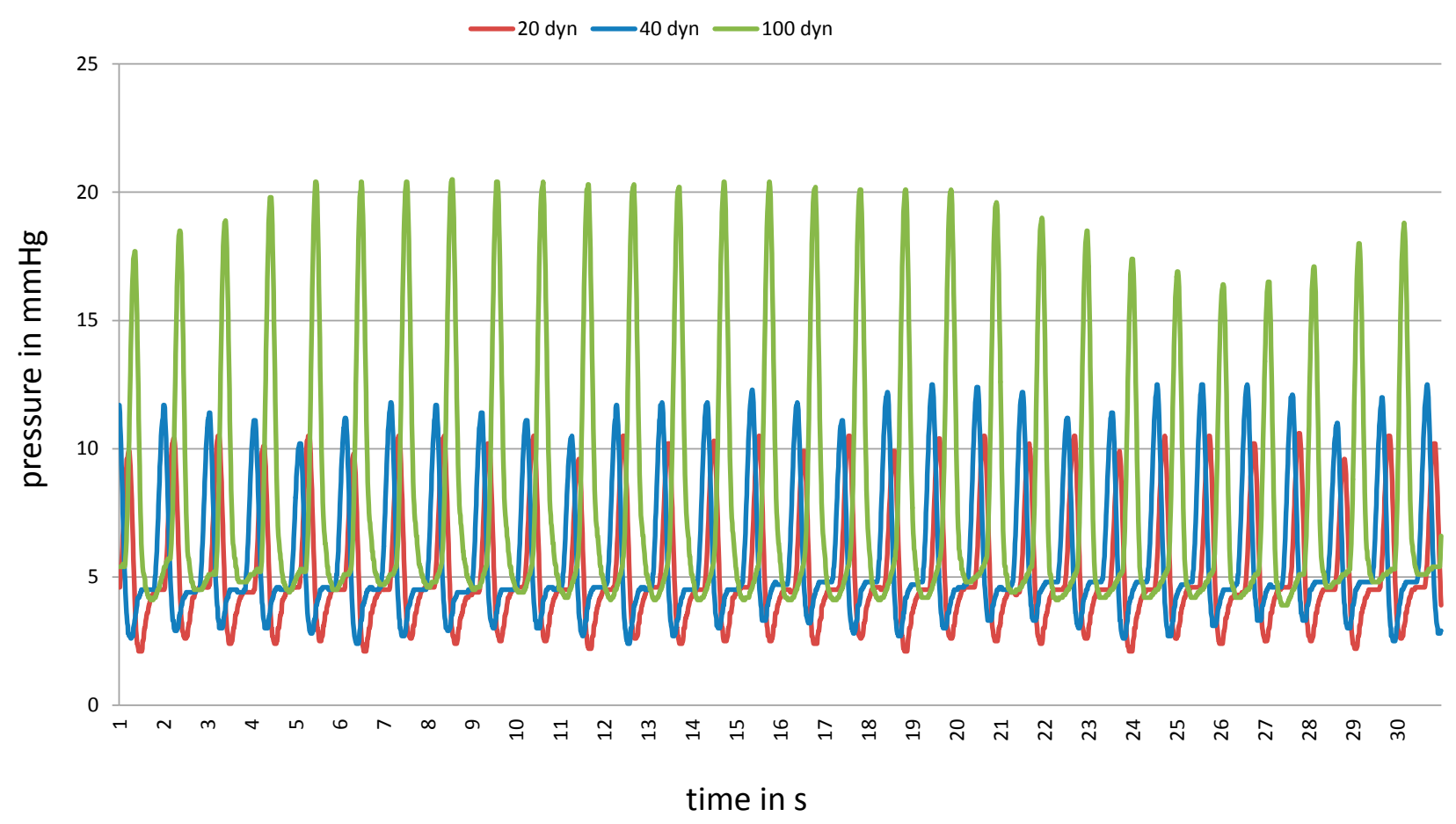


Table 1. Minimal, maximal and average pressure in the polyurethane (PU) scaffold under different shear stress values and with or without pulsation of the BR.

\begin{tabular}{|c|c|c|c|c|}
\hline & $\begin{array}{c}\text { Shear Stress } \\
\left(\mathrm{dyn} / \mathrm{cm}^{2}\right)\end{array}$ & $\begin{array}{c}\text { Pressure }_{\text {min }} \\
(\mathrm{mmHg})\end{array}$ & $\begin{array}{c}\text { Pressure }_{\max } \\
(\mathrm{mmHg})\end{array}$ & $\begin{array}{c}\text { Pressure }_{\text {average }} \\
(\mathrm{mmHg})\end{array}$ \\
\hline \multirow{4}{*}{ Without pulsation } & 10 & 5.1 & 5.5 & 5.4 \\
\hline & 20 & 5.6 & 5.9 & 5.8 \\
\hline & 40 & 5.7 & 6.1 & 5.9 \\
\hline & 100 & 6.2 & 6.7 & 6.5 \\
\hline \multirow{3}{*}{ With pulsation } & 20 & 2.1 & 10.6 & 5.2 \\
\hline & 40 & 2.4 & 12.5 & 5.7 \\
\hline & 100 & 3.9 & 20.5 & 8.0 \\
\hline
\end{tabular}

As shown in Figure 8b the seeding device rotates on the mixer to ensure uniform cell seeding all over the scaffold's surface. The media reservoir guarantees a sufficient nutrient supply for the cells during cultivation. Gas exchange takes place through the silicone tubes and a sterile filter on top of the screw cap. The flow rate can be adjusted by regulating the pump speed during the run with the potentiometer. The pump allows a slow increase of the shear stress from $5 \mathrm{dyn} / \mathrm{cm}^{2}$ up to $100 \mathrm{dyn} / \mathrm{cm}^{2}$ to enable cell adaption to shear stress and the development of an ECM. The control unit routes a workflow to actuate the pump, the pulse generator and the rotating mixer. The roller pump enables a mildly pulsing flow through the seeded vascular graft while the pulse generator mimics heartbeat with 60 beats per minute as shown in Figure 10. It could be shown that the bioreactor provides sufficient control of the flow characteristics inside the scaffold and a pressure-time curve with physiologic characteristics.

The combination of these features in one BR, which is easy to handle and works properly in a standard incubator is unique.

\subsection{Experimental Evaluation of the Bioreactor}

FBs and ECs from the vena saphena magna can be isolated rapidly in large quantities, expanded extensively in culture and can be well recovered after repeated freezing/thawing cycles. As previously described [56], cells from this source are already used successfully for seeding of PU heart valve scaffolds. Peck et al. [57] note that the costs for a TEVG grows with its complexity. The use of ECs would reduce time and effort in the production of TEVGs. However, Feugier et al. [58] postulated the benefit of coating scaffolds with extra cellular matrix (ECM) proteins to raise ECs adherence. Furthermore fibronectin, laminin, and tenascin-C splice variants, proteins of the ECM, are known to promote neoangiogenesis and endothelial differentiation [59-61]. FBs are mesenchymal cells and synthesize these proteins. Moreover, the adventitia contributes in vascular tone. In this context, Laflamme et al. demonstrated that a tissue engineered vascular adventitia, reconstructed with vascular fibroblasts derived from human adventitia, has the capability of contraction and relaxing [62].

The two scaffold materials for cell seeding compared in this study differ in structure and chemical composition. SEM analysis (Figure 11) of native PU showed a fine meshwork of polyurethane fibers (a), while collagen scaffolds revealed a smooth topography (b). In accordance with results from Gulbins et al. [23], seeded PU revealed a cobblestone-morphology (c), indicating the presence of ECs 
coating. Collagen (d) showed insufficient cell adherence (arrows pointing on attached cells), resulting in widely bare scaffold surfaces.

Figure 11. Scanning electron microscopy (SEM) analysis of polyurethane (a) and collagen $(\mathbf{b})$ before $(\mathbf{a}+\mathbf{b})$ and after $(\mathbf{c}+\mathbf{d})$ rotational seeding. Whilst PU shows cell adherence all over the scaffolds surface (c), collagen (d) is seeded only partially (arrows). These are representative images of an experiment in triplicates.
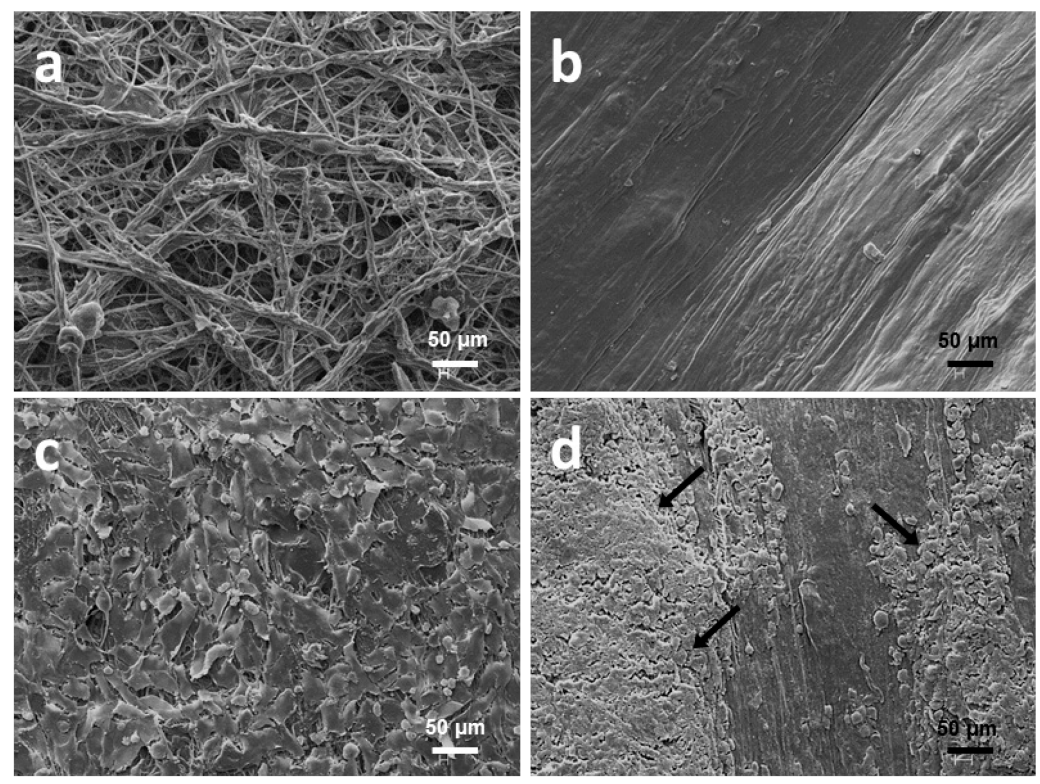

In contrast to our findings, Buttafoca et al. [63] could create a complete layer of smooth muscle cells within 7 days. But instead of collagen tubes, they used a hybrid of the copolymer P(DLLA-coTMC) (D,L-lactide and trimethylene carbonate) and collagen for the purpose of generating a scaffold that is more stable than a purely collagen one. So the scaffold possessed a clearly porous surface that might have supported the cells adherence.

In line with the SEM results, a confluent cell layer was detected on the PU scaffolds under immunohistochemical examination. Staining against FB-specific TE-7 revealed a confluent coverage with FB on PU (Figure 12a). The staining for EC-specific CD31 (c) is partial and weak, indicating that ECs lose cell-cell-contacts [64] during static cultivation on PU.

Collagen (b) did not show positive staining for TE-7 on its surface, indicating the absence of FBs. In contrast, ECs were evenly spread on collagen (d) confirming the findings of the SEM analysis.

While the porous nature of PU supports cell attachment, the smooth surface of collagen seems to hamper cell adherence. This might be explained by shear stress during EC-injection to the scaffold's lumen, resulting in the loss of insufficiently attached FBs on collagen.

As shown in Figure 13, SEM analysis of seeded PU after preliminary perfusion experiments under pulsatile flow conditions $\left(100 \mathrm{dyn} / \mathrm{cm}^{2}\right)$ revealed a disrupted cell layer (a). A closer look showed a smooth cell surface and an orientation in flow direction after dynamic cultivation. IHC analysis demonstrated a partial seeding of PU with slight staining for CD31 (b) and TE-7 (c). Due to these results and the fact that the mean shear stress in small venules tends to be from 20 to $40 \mathrm{dyn} / \mathrm{cm}^{2}$ [31], we adapted the perfusion protocol. 
Figure 12. Immunohistochemical (IHC) analysis of dynamically seeded PU and collagen after EC-specific CD31 (a + b, red) and FB-specific TE-7 $(\mathbf{c}+\mathbf{d}$, red) staining. Positively stained cells are highlighted with arrows. Cell nuclei were stained with hemalaun. These are representative images of an experiment in triplicates.

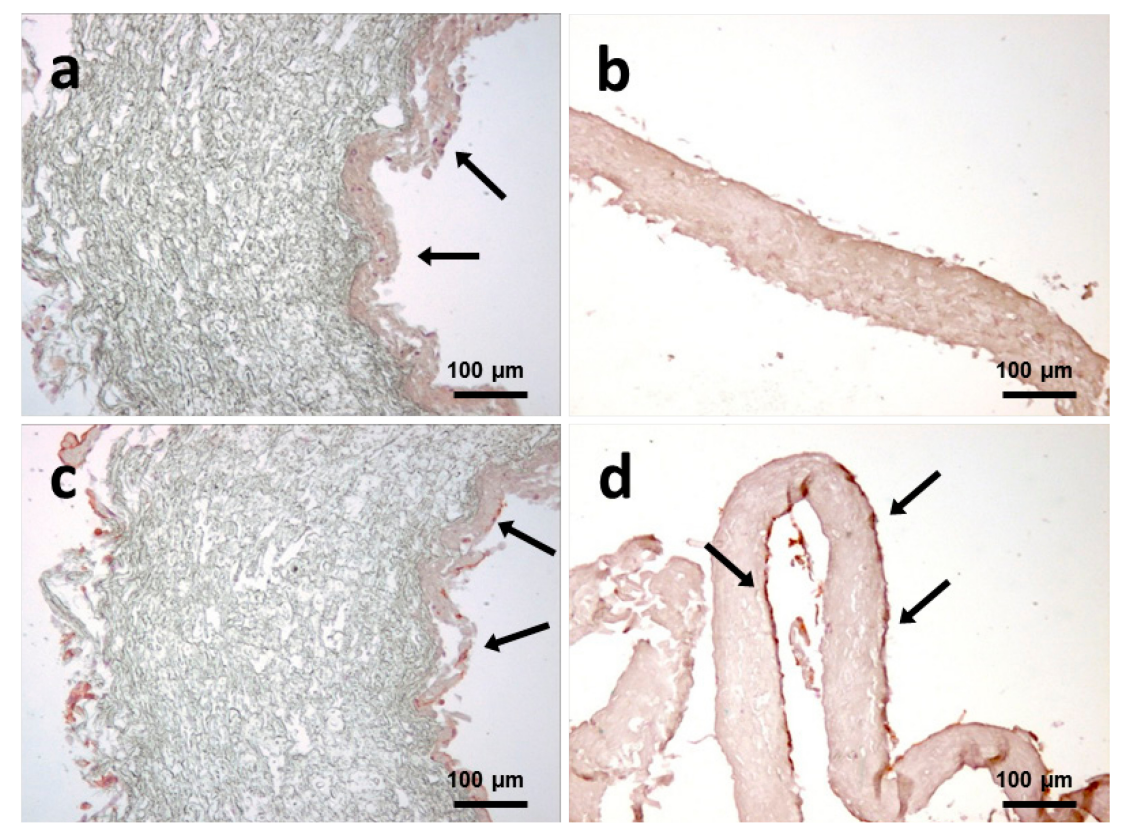

Figure 13. SEM (a) and IHC analysis $(\mathbf{b}=\mathrm{TE}-7, \mathbf{c}=\mathrm{CD} 31)$ of seeded PU after flow exposure $\left(100 \mathrm{dyn} / \mathrm{cm}^{2}\right)$ in the bioreactor system show single cells on the surface of the scaffolds.
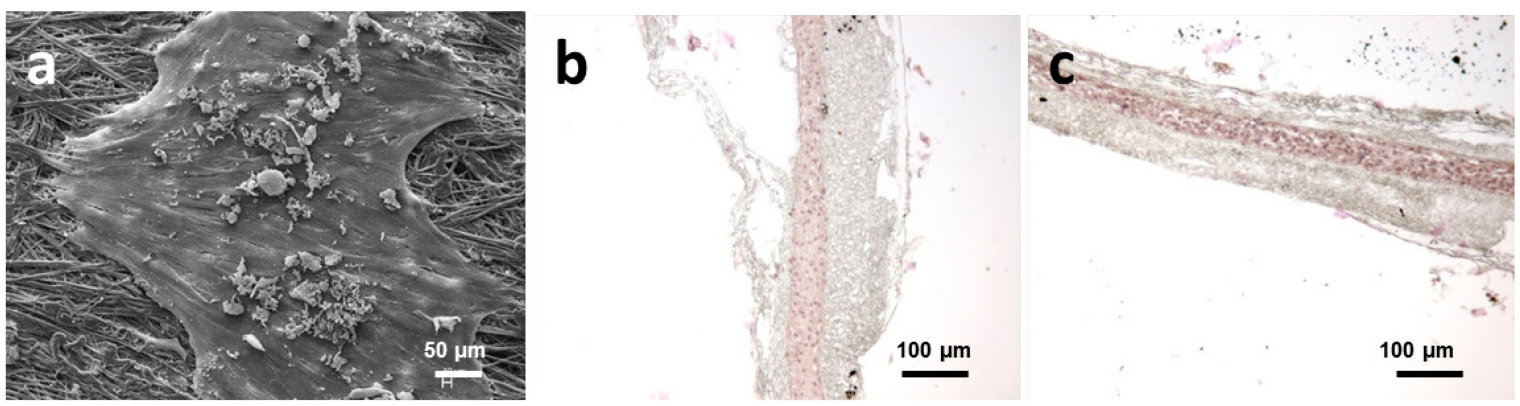

Figure 14. SEM (a) and IHC analysis $(\mathbf{b}=\mathrm{TE}-7, \mathbf{c}=\mathrm{CD} 31)$ of seeded PU after flow exposure $\left(10\right.$ to $\left.40 \mathrm{dyn} / \mathrm{cm}^{2}\right)$ in the all-in-one bioreactor system show a confluent and flattened lining with ECs $(\mathbf{a}, \mathbf{c})$ and FBs $(\mathbf{b})$. These are representative images of an experiment in triplicates.
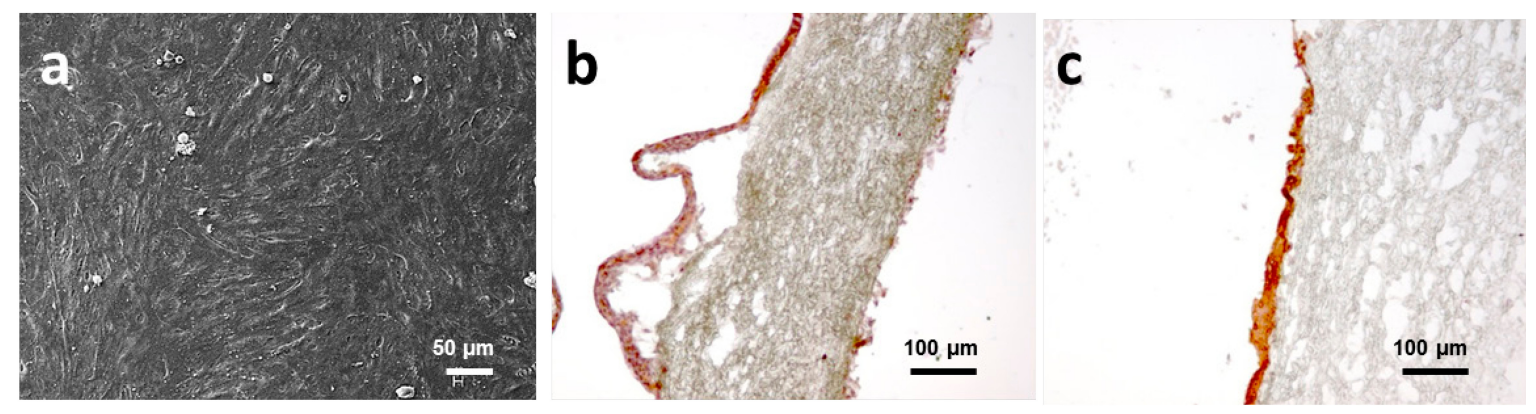
Ballermann et al. [31] demonstrated that ECs cultivated for 9 days with $15 \mathrm{dyn} / \mathrm{cm}^{2}$ showed a significantly better adherence than cells cultivated under the same conditions with $1 \mathrm{dyn} / \mathrm{cm}^{2}$. Based on this finding we started conditioning with a shear stress of $10 \mathrm{dyn} / \mathrm{cm}^{2}$ and then increased it stepwise up to $40 \mathrm{dyn} / \mathrm{cm}^{2}$. In contrast to other groups [42,65] we cultivated the cells with an up to 4-fold higher shear stress. As shown in Figure 14, SEM analysis of seeded PU revealed a confluent cellular coating of the scaffolds (a). After flow exposure, the cell layer is flattened and smoother than under static conditions. IHC showed a defined cell multilayer with moderate staining for TE-7 (b) and a high expression of CD31 (c).

\section{Conclusions}

The novel BR for the use in a conventional incubator combines seeding and conditioning of two vascular prostheses in a unique fashion. It provides a new tool for simultaneous seeding, conditioning and perfusion of multiple small-diameter TEVGs. This system allows the development of cell-based cardiovascular devices for in vitro evaluation studies as well.

The results of the first experiments demonstrated a successful and easy sterile process that allows cell evaluation within 5 days. This first proof of concept offers further approaches to a routine application in TEVG laboratory research processes. Future experiments are still required to evaluate the influence of flow and pulse rates on the formation of stable layers on various scaffold materials. Additionally, the impact of these parameters on cellular gene expression and scaffolds mechanics has to be assessed.

\section{Acknowledgments}

We would like to thank Viscofan Bioengineering $\mathrm{GmbH}$ for kind appropriation of collagen tubes.

\section{Author Contributions}

Julia Schulte performed all cell culturing experiments, optimized the bioreactor, wrote the manuscript and performed data analyses. Anja Friedrich developed the prototype of the bioreactor and supported the writing of the manuscript. Trixi Hollweck supported the writing of the manuscript and data analyses. Fabian König supported and implemented changes to the bioreactor setup by using a CATIA Software. Markus Eblenkamp supervised the technical construction done by Anja Friedrich. Andres Beiras-Fernandez supported the whole project from a clinical point of view. Cornelia Fano developed and optimized the polyurethane scaffolds. Christian Hagl is the clinical director of the heart surgery who has provided essential clinical input to the project. Bassil Akra conceived the experimental study, was the project owner, the device inventor, the group leader and overall supervisor. All authors read and approved the final manuscript.

\section{Conflicts of Interest}

The authors declare no conflict of interest. 


\section{References}

1. WHO. Causes of Death 2008 Summary Tables; Health Statistics and Informatics Department: Geneva, Switzerland, 2011.

2. Löwel, H. Koronare Herzkrankheit und akuter Myokardinfarkt. In Gesundheitsberichterstattung des Bundes; Robert Koch-Institut: Berlin, Germany, 2006; Heft 33 (In German).

3. Ku, D.N.; Allen, R.C. Vascular Grafts. In Tissue Engineering and Artificial Organs, 3rd ed.; Brozino, J.D., Ed.; The Biomedical Engineering Handbook, Third Edition; CRC Press: Boca Raton, FL, USA, 2006.

4. Aper, T.; Haverich, A.; Teebken, O. New developments in tissue engineering of vascular prosthetic grafts. Vasa 2009, 38, 99-122.

5. Takayama, T.; Hiro, T.; Hirayama, A. Is angioplasty able to become the gold standard of treatment beyond bypass surgery for patients with multivessel coronary artery disease? Therapeutic strategies for 3-vessel coronary artery disease: OPCAB vs. PCI(PCI-Side). Circ. J. 2010, 74, 2744-2749.

6. Sündermann, S.H.; Salzberg, S.P. Renaissance of surgery for coronary artery disease. Praxis (Bern 1994) 2011, 100, 23-28.

7. Daemen, J.; Boersma, E.; Flather, M.; Booth, J.; Stables, R.; Rodriguez, A.; Rodriguez-Granillo, G.; Hueb, W.A.; Lemos, P.A.; Serruys, P.W. Long-term safety and efficacy of percutaneous coronary intervention with stenting and coronary artery bypass surgery for multivessel coronary artery disease: A meta-analysis with 5-year patient-level data from the ARTS, ERACI-II, MASS-II, and SoS trials. Circulation 2008, 118, 1146-1154.

8. Guyton, R.A. Coronary artery bypass is superior to drug-eluting stents in multivessel coronary artery disease. Ann. Thorac. Surg. 2006, 81, 1949-1957.

9. Cohen, D.J.; Lavelle, T.A.; van Hout, B.; Li, H.; Lei, Y.; Robertus, K.; Pinto, D.; Magnuson, E.A.; McGarry, T.F.; Lucas, S.K.; et al. Economic outcomes of percutaneous coronary intervention with drug-eluting stents versus bypass surgery for patients with left main or three-vessel coronary artery disease: One-year results from the SYNTAX trial. Catheter. Cardiovasc. Interv. 2012, 79, 198-209.

10. Cohen, D.J.; van Hout, B.; Serruys, P.W.; Mohr, F.W.; Macaya, C.; den Heijer, P.; Vrakking, M.M.; Wang, K.; Mahoney, E.M.; Audi, S.; et al. Quality of life after PCI with drug-eluting stents or coronary-artery bypass surgery. N. Engl. J. Med. 2011, 364, 1016-1026.

11. Moneta, G.L.; Porter, J.M. Arterial substitutes in peripheral vascular surgery: A review. J. Long Term Eff. Med. Implants 1995, 5, 47-67.

12. Burkel, W.E. The challenge of small diameter vascular grafts. Med. Prog. Technol. 1988, 14, 165-175.

13. Peppas, N.A.; Langer, R. New challenges in biomaterials. Science 1994, 263, 1715-1720.

14. Zhou, M.; Liu, Z.; Liu, C.; Jiang, X.; Wei, Z.; Qiao, W.; Ran, F.; Wang, W.; Qiao, T.; Liu, C. Tissue engineering of small-diameter vascular grafts by endothelial progenitor cells seeding heparin-coated decellularized scaffolds. J. Biomed. Mater. Res. Part B 2012, 100, 111-120.

15. Wood, S.C.; Tang, X.; Tesfamariam, B. Paclitaxel potentiates inflammatory cytokine-induced prothrombotic molecules in endothelial cells. J. Cardiovasc. Pharmacol. 2010, 55, 276-285. 
16. Kannan, R.Y.; Salacinski, H.J.; Butler, P.E.; Hamilton, G.; Seifalian, A.M. Current status of prosthetic bypass grafts: A review. J. Biomed. Mater. Res. Part B 2005, 74, 570-581.

17. Yazdani, S.K.; Tillman, B.W.; Berry, J.L.; Soker, S.; Geary, R.L. The fate of an endothelium layer after preconditioning. J. Vasc. Surg. 2010, 51, 174-183.

18. Kerdjoudj, H.; Moby, V.; Berthelemy, N.; Gentils, M.; Boura, C.; Bordenave, L.; Stoltz, J.F.; Menu, P. The ideal small arterial substitute: Role of cell seeding and tissue engineering. Clin. Hemorheol. Microcirc. 2007, 37, 89-98.

19. Bourget, J.M.; Gauvin, R.; Larouche, D.; Lavoie, A.; Labbe, R.; Auger, F.A.; Germain, L. Human fibroblast-derived ECM as a scaffold for vascular tissue engineering. Biomaterials 2012, 33, 9205-9213.

20. Gulbins, H.; Goldemund, A.; Anderson, I.; Haas, U.; Uhlig, A.; Meiser, B.; Reichart, B. Preseeding with autologous fibroblasts improves endothelialization of glutaraldehyde-fixed porcine aortic valves. J. Thorac. Cardiovasc. Surg. 2003, 125, 592-601.

21. DiMuzio, P.; Fischer, L.; McIlhenny, S.; DiMatteo, C.; Golesorhki, N.; Grabo, D.; Tarola, N.; Mericli, A.; Shapiro, I.; Tulenko, T. Development of a tissue-engineered bypass graft seeded with stem cells. Vascular 2006, 14, 338-342.

22. Kawamoto, A.; Asahara, T. Role of progenitor endothelial cells in cardiovascular disease and upcoming therapies. Catheter. Cardiovasc. Interv. 2007, 70, 477-484.

23. Gulbins, H.; Pritisanac, A.; Dauner, M.; Petzold, R.; Goldemund, A.; Doser, M.; Meiser, B.; Reichart, B. Seeding of human vascular cells onto small diameter polyurethane vascular grafts. Thorac. Cardiovasc. Surg. 2006, 54, 102-107.

24. Alison, M.R.; Poulsom, R.; Forbes, S.; Wright, N.A. An introduction to stem cells. J. Pathol. 2002, 197, 419-423.

25. Martin-Rendon, E.; Watt, S.M. Exploitation of stem cell plasticity. Transfus. Med. 2003, 13, 325-349.

26. Ringe, J.; Kaps, C.; Burmester, G.R.; Sittinger, M. Stem cells for regenerative medicine: Advances in the engineering of tissues and organs. Die Naturwissenschaften 2002, 89, 338-351.

27. Zimmermann, W.H.; Eschenhagen, T. Cardiac tissue engineering for replacement therapy. Heart Fail. Rev. 2003, 8, 259-269.

28. Petit-Zeman, S. Regenerative medicine. Nat. Biotechnol. 2001, 19, 201-206.

29. Pittenger, M.F.; Mackay, A.M.; Beck, S.C.; Jaiswal, R.K.; Douglas, R.; Mosca, J.D.; Moorman, M.A.; Simonetti, D.W.; Craig, S.; Marshak, D.R. Multilineage potential of adult human mesenchymal stem cells. Science 1999, 284, 143-147.

30. Matsumura, G.; Hibino, N.; Ikada, Y.; Kurosawa, H.; Shin'oka, T. Successful application of tissue engineered vascular autografts: Clinical experience. Biomaterials 2003, 24, 2303-2308.

31. Ballermann, B.J.; Dardik, A.; Eng, E.; Liu, A. Shear stress and the endothelium. Kidney Int. Suppl. 1998, 67, S100-S108.

32. Solan, A.; Dahl, S.L.; Niklason, L.E. Effects of mechanical stretch on collagen and cross-linking in engineered blood vessels. Cell Transpl. 2009, 18, 915-921.

33. Barron, V.; Lyons, E.; Stenson-Cox, C.; McHugh, P.E.; Pandit, A. Bioreactors for cardiovascular cell and tissue growth: A review. Ann. Biomed. Eng. 2003, 31, 1017-1030. 
34. Lee, D.J.; Steen, J.; Jordan, J.E.; Kincaid, E.H.; Kon, N.D.; Atala, A.; Berry, J.; Yoo, J.J. Endothelialization of heart valve matrix using a computer-assisted pulsatile bioreactor. Tissue Eng. Part A 2009, 15, 807-814.

35. Chen, H.C.; Hu, Y.C. Bioreactors for tissue engineering. Biotechnol. Lett. 2006, 28, 1415-1423.

36. Morsi, Y.S.; Yang, W.W.; Owida, A.; Wong, C.S. Development of a novel pulsatile bioreactor for tissue culture. J. Artif. Org. 2007, 10, 109-114.

37. Wendt, D.; Riboldi, S.A.; Cioffi, M.; Martin, I. Bioreactors in tissue engineering: Scientific challenges and clinical perspectives. Adv. Biochem. Eng. Biotechnol. 2009, 112, 1-27.

38. Chlupac, J.; Filova, E.; Bacakova, L. Blood vessel replacement: 50 years of development and tissue engineering paradigms in vascular surgery. Physiol. Res. Acad. Sci. Bohemoslov. 2009, 58 (Suppl. 2), S119-S139.

39. Rademacher, A.; Paulitschke, M.; Meyer, R.; Hetzer, R. Endothelialization of PTFE vascular grafts under flow induces significant cell changes. Int. J. Artif. Org. 2001, 24, 235-242.

40. Martin, I.; Smith, T.; Wendt, D. Bioreactor-based roadmap for the translation of tissue engineering strategies into clinical products. Trends Biotechnol. 2009, 27, 495-502.

41. Bilodeau, K.; Couet, F.; Boccafoschi, F.; Mantovani, D. Design of a perfusion bioreactor specific to the regeneration of vascular tissues under mechanical stresses. Artif. Org. 2005, 29, 906-912.

42. Dunkern, T.R.; Paulitschke, M.; Meyer, R.; Buttemeyer, R.; Hetzer, R.; Burmester, G.; Sittinger, M. A novel perfusion system for the endothelialisation of PTFE grafts under defined flow. Eur. J. Vasc. Endovasc. Surg. 1999, 18, 105-110.

43. Heydarkhan-Hagvall, S.; Esguerra, M.; Helenius, G.; Soderberg, R.; Johansson, B.R.; Risberg, B. Production of extracellular matrix components in tissue-engineered blood vessels. Tissue Eng. 2006, 12, 831-842.

44. Sodian, R.; Lemke, T.; Fritsche, C.; Hoerstrup, S.P.; Fu, P.; Potapov, E.V.; Hausmann, H.; Hetzer, R. Tissue-engineering bioreactors: A new combined cell-seeding and perfusion system for vascular tissue engineering. Tissue Eng. 2002, 8, 863-870.

45. Williams, C.; Wick, T.M. Perfusion bioreactor for small diameter tissue-engineered arteries. Tissue Eng. 2004, 10, 930-941.

46. Arrigoni, C.; Chitto, A.; Mantero, S.; Remuzzi, A. Rotating versus perfusion bioreactor for the culture of engineered vascular constructs based on hyaluronic acid. Biotechnol. Bioeng. 2008, 100, 988-997.

47. Engbers-Buijtenhuijs, P.; Buttafoco, L.; Poot, A.A.; Dijkstra, P.J.; de Vos, R.A.; Sterk, L.M.; Geelkerken, R.H.; Vermes, I.; Feijen, J. Biological characterisation of vascular grafts cultured in a bioreactor. Biomaterials 2006, 27, 2390-2397.

48. Hahn, M.S.; McHale, M.K.; Wang, E.; Schmedlen, R.H.; West, J.L. Physiologic pulsatile flow bioreactor conditioning of poly(ethylene glycol)-based tissue engineered vascular grafts. Ann. Biomed. Eng. 2007, 35, 190-200.

49. Aleksieva, G.; Hollweck, T.; Thierfelder, N.; Haas, U.; Koenig, F.; Fano, C.; Dauner, M.; Wintermantel, E.; Reichart, B.; Schmitz, C.; et al. Use of a special bioreactor for the cultivation of a new flexible polyurethane scaffold for aortic valve tissue engineering. Biomed. Eng. Online 2012, 11, doi:10.1186/1475-925X-11-92. 
50. Huang, A.H.; Niklason, L.E. Engineering biological-based vascular grafts using a pulsatile bioreactor. J. Vis. Exp. 2011, doi:10.3791/2646.

51. Thompson, C.A.; Colon-Hernandez, P.; Pomerantseva, I.; MacNeil, B.D.; Nasseri, B.; Vacanti, J.P.; Oesterle, S.N. A novel pulsatile, laminar flow bioreactor for the development of tissue-engineered vascular structures. Tissue Eng. 2002, 8, 1083-1088.

52. Massai, D.; Cerino, G.; Gallo, D.; Pennella, F.; Deriu, M.A.; Rodriguez, A.; Montevecchi, F.M.; Bignardi, C.; Audenino, A.; Morbiducci, U. Bioreactors as engineering support to treat cardiac muscle and vascular disease. J. Healthc. Eng. 2013, 4, 329-370.

53. Peterson, A.; Landeen, L.K.; Bennett, J.; Gee, G.; Chesla, S.; Zeltinger, J.; Flatt, J.H.; Applegate, M.A.; Dunkelman, N.; Kemmerrer, S. Aparatus and Method for Simulating in vivo Conditions While Seeding and Culturing Three-Dimensional Tissue Constructs. U.S. Patent 6,121,042, 19 September 2000.

54. Syedain, Z.H.; Meier, L.A.; Bjork, J.W.; Lee, A.; Tranquillo, R.T. Implantable arterial grafts from human fibroblasts and fibrin using a multi-graft pulsed flow-stretch bioreactor with noninvasive strength monitoring. Biomaterials 2011, 32, 714-722.

55. Hsu, S.H.; Tsai, I.J.; Lin, D.J.; Chen, D.C. The effect of dynamic culture conditions on endothelial cell seeding and retention on small diameter polyurethane vascular grafts. Med. Eng. Phys. 2005, 27, 267-272.

56. Akra, B.; Uhlig, A.; Haas, U.; Fano, C.; Dauner, M.; Lohse, P.; Gulbins, H.; Meiser, B.; Eissner, G.; Reichart, B.; et al. Perfusion Bioreactor: A New Pulsatile System for the Perfusion of Tissue Engineered Cardiovascular Prostheses. In World Congress on Medical Physics and Biomedical Engineering, September 7-12, 2009, Munich, Germany; Magjarevic, R., Ed.; Springer: Berlin, Germany, 2009; Volume 25/10, pp. 7-8.

57. Peck, M.; Gebhart, D.; Dusserre, N.; McAllister, T.N.; L'Heureux, N. The Evolution of Vascular Tissue Engineering and Current State of the Art. Cells Tissues Org. 2012, 195, 144-158.

58. Feugier, P.; Black, R.A.; Hunt, J.A.; How, T.V. Attachment, morphology and adherence of human endothelial cells to vascular prosthesis materials under the action of shear stress. Biomaterials 2005, 26, 1457-1466.

59. Ballard, V.L.; Sharma, A.; Duignan, I.; Holm, J.M.; Chin, A.; Choi, R.; Hajjar, K.A.; Wong, S.C.; Edelberg, J.M. Vascular tenascin-C regulates cardiac endothelial phenotype and neovascularization. FASEB J. 2006, 20, 717-719.

60. Corda, S.; Samuel, J.L.; Rappaport, L. Extracellular matrix and growth factors during heart growth. Heart Fail Rev. 2000, 5, 119-130.

61. Hallmann, R.; Horn, N.; Selg, M.; Wendler, O.; Pausch, F.; Sorokin, L.M. Expression and function of laminins in the embryonic and mature vasculature. Physiol. Rev. 2005, 85, 979-1000.

62. Laflamme, K.; Roberge, C.J.; Grenier, G.; Remy-Zolghadri, M.; Pouliot, S.; Baker, K.; Labbe, R.; D’Orleans-Juste, P.; Auger, F.A.; Germain, L. Adventitia contribution in vascular tone: Insights from adventitia-derived cells in a tissue-engineered human blood vessel. FASEB J. 2006, 20, 1245-1247.

63. Buttafoco, L.; Boks, N.P.; Engbers-Buijtenhuijs, P.; Grijpma, D.W.; Poot, A.A.; Dijkstra, P.J.; Vermes, I.; Feijen, J. Porous hybrid structures based on P(DLLA-co-TMC) and collagen for tissue engineering of small-diameter blood vessels. J. Biomed. Mater. Res. Part B 2006, 79, 425-434. 
64. Newman, P.J. The role of PECAM-1 in vascular cell biology. Ann. N. Y. Acad. Sci. 1994, 714, $165-174$.

65. McIlhenny, S.E.; Hager, E.S.; Grabo, D.J.; DiMatteo, C.; Shapiro, I.M.; Tulenko, T.N.; DiMuzio, P.J. Linear shear conditioning improves vascular graft retention of adipose-derived stem cells by upregulation of the $\alpha 5 \beta 1$ integrin. Tissue Eng. Part A 2010, 16, 245-255.

(C) 2014 by the authors; licensee MDPI, Basel, Switzerland. This article is an open access article distributed under the terms and conditions of the Creative Commons Attribution license (http://creativecommons.org/licenses/by/3.0/). 